\title{
Tumour necrosis factor and anti-tumour necrosis factor approach to inflammatory demyelinating diseases of the central nervous system
}

\author{
Krzysztof W Selmaj
}

Multiple sclerosis is a primary demyelinating disease in which an inflammatory cell infiltrate represents a characteristic pathological feature of active lesions within the central nervous system (CNS). As the search for anti-myelin antibodies in multiple sclerosis has thus far been unsuccessful, the possibility is raised that cell mediated immune mechanisms orchestrate the pathogenesis of this disease. ${ }^{1}$ In cellular immune mechanisms cytokines play a particularly important part. Tumour necrosis factors (TNFs) form a unique family of cytokines that are very pleiotropic in nature. ${ }^{2}$ TNFs demonstrate immunoregulatory activity but they are also involved in the effector arm of cellular immune responses. TNF increases antigen and mitogen induced $\mathrm{T}$ lymphocyte activation, ${ }^{3}$ as well as increasing the generation of cytotoxic $\mathrm{T}$ cells. ${ }^{4}$ Studies both in vitro and in vivo have suggested a role for TNFs in the pathology of multiple sclerosis. In this report, I will summarise data for and against involvement of TNFs in the mechanisms of multiple sclerosis and attempt to apply an anti-TNF approach for future therapeutic strategy for this disease.

\section{Organotypic nerve tissue cultures}

An initial interest of $\mathrm{TNF} \alpha$ involvement in the pathomechanisms of multiple sclerosis was generated after demonstration that $\mathrm{TNF} \alpha$ was capable of inducing delayed onset myelin dilatation and subsequent gradual myelin degradation in organotypic nerve tissue cultures. ${ }^{5}$ The organotypic nerve tissue cultures have been established from spinal cord tissue explanted from mice embryos. Several cytokines, $\mathrm{TNF} \alpha$, interferon $\gamma$, interleukin 1 , interleukin 2 , interleukin 6 were added to spinal cord cultures at a time when myelination was well advanced. The cultures were examined in living state and after fixation by light and electron microscopy. In the living state, cultures exposed to $\mathrm{TNF} \alpha$ showed selective damage to myelin. By light microscopy, myelinated fibres exhibited dilatations of myelin sheath. These swellings were regularly spaced along affected fibres and appeared after 18 hours of exposure. Withdrawal of $\mathrm{TNF} \alpha$ did not reverse the effect. Instead, more advanced myelin degradation was observed. Light microscopy of epoxy sections revealed that the myelin swelling involved an increase in the periaxonal space in such a way as to leave the axon intact but in large part separating it from its myelin sheaths. Oligodendroglia displayed less cytoplasm than usual and had fewer processes, in comparison with control cultures. By electron microscopy, it could be seen that within the dilated myelin sheaths, the axon was closely applied unilaterally, resting in a furrow of oligodendroglial cytoplasm. At the early stage of TNF induced changes, the myelin sheath was affected to a lesser degree, a normal periodicity was usually retained, presumably attributable to myelin slippage, and circumferential contact with the axon was lost, leaving a wide periaxinal space. At later time points, the majority of myelin sheaths progressed to degeneration, whereupon the debris was phagocytosed by surrounding reactive astrocytes. Astrocytes displayed considerable hypertrophy. Spinal cord explants treated with other cytokines showed few pathological alternations and were indistinguishable from control cultures.

\section{Glial cell cultures}

OLIGODENDROCYTE

It is well known that oligodendrocytes are selectively depleted from chronically demyelinating multiple sclerosis lesions, whereas astrocytes are spared and may be proliferative. This led to the concept of a specific immunologically mediated destruction of oligodendrocytes in multiple sclerosis. The cytotoxic effect of recombinant cytokines was tested on glial cells cultured from mature bovine brain. LT $\alpha$ and $\mathrm{TNF} \alpha$ induced injury to oligodendrocytes in a time and dose dependent fashion. ${ }^{6}$ The other cytokines tested, interferon $\gamma$, IL2 and IL6, did not affect oligodendrocytes in culture over a 72 hour observation period. LT $\alpha$ showed a more potent cytotoxicity than $\mathrm{TNF} \alpha$ toward oligodendrocytes. Morphological studies showed that the LT $\alpha$ mediated effects were associated with early retraction of cell processes, depolymerisation of $\mathrm{F}$-actin and subsequent nuclear degeneration. Lack of early cytoplasmic membrane injury as measured by ${ }^{51} \mathrm{CR}$ release and electron microscope studies demonstrating nuclear disintegration suggested an apoptotic mechanism of oligodendrocyte injury evoked by LT $\alpha$, which was supported by DNA integrity assay. The above results demonstrate that LT $\alpha$ possesses potent cytotoxic activity against oligodendrocytes and that the major mechanism involved in this process is DNA fragmentation.

\section{ASTROCYTE}

Reactive gliosis is a prominent pathological feature in multiple sclerosis where reactive astrocytes constitute the major cell type in demyelinating plaques. The effect of cytokines on astrocytes cultured from mature bovine 
brain was determined both in a serum containing medium and in a chemically defined medium. ${ }^{7}$ The results showed that in serum free medium, $\mathrm{TNF} \alpha$ and, to a lesser degree, IL6 and LT $\alpha$, were mitogenic for astrocytes. Increased uptake of $[3 \mathrm{H}]$ thymidine could be detected within 36 hours in vitro and its presence in astrocytes was confirmed by autoradiography. In contrast, neither IL $1 \alpha$ nor IL $1 \beta$ induced astrocyte proliferation in serum free medium but showed some synergistic effect with serum. None of the cytokines tested was toxic for astrocytes as measured by ${ }^{51} \mathrm{Cr}$ release. The results support a role of TNFs in the development of astrocyte proliferation that may contribute to the reactive gliosis found in white matter diseases of the central nervous system such as multiple sclerosis.

\section{Immunocytochemistry of multiple sclerosis plaques}

To detect TNFs, early postmortem material was applied from several multiple sclerosis cases. Using acetone fixed frozen sections and the avidin-biotin-complex technique, $\mathrm{TNF} \alpha$ and LT $\alpha$ were identified in acute and chronic active multiple sclerosis lesions but were absent from chronic silent lesions suggesting their involvement in lesion formation. ${ }^{8}$ Immunoreactivity for both cytokines was noted principally with cells at the edge of the lesions, but showed different patterns of cellular localisation. Antibodies to LT $\alpha$ reacted with $\mathrm{CD} 3$ lymphocytes and microglial cell, whereas antibodies to $\mathrm{TNF} \alpha$ reacted with astrocytes and foamy macrophages, and infrequently with endothelial cells at the lesion edge in acute lesions. Quantitation of LT $\alpha$ and TNF $\alpha$ positive cells in the spleen and peripheral blood by immunocytochemistry and FACS analysis demonstrated no increase in the number of these cells, suggesting that the expression of TNFs occurs locally within the CNS.

\section{TNF levels in the CSF}

Although earlier studies failed to detect $\mathrm{TNF} \alpha$ in the CSF of multiple sclerosis patients ${ }^{10}$ subsequent studies using a proteinase inhibitor to prevent TNF degradation provided evidence on the increased levels of TNF $\alpha$ in the CSF in multiple sclerosis. ${ }^{112}$ In one of these studies it has found significantly higher levels of $\mathrm{TNF} \alpha$ in the CSF of patients with chronic progressive multiple sclerosis than in patients with stable multiple sclerosis or with other neurological disease. ${ }^{12}$ Cerebrospinal fluid levels of TNF $\alpha$ were also correlated with the degree of disability in patients with progressive disease, and high levels predicted a poor prognosis during a 24 month period of observation. The finding that high levels of TNF $\alpha$ in the CSF of chronic progressive MS patients did not correspond to serum levels of $\mathrm{TNF} \alpha$ suggested that TNF is produced locally within the CNS. Furthermore, the lack of correlation between the presence of pleocytosis and $\mathrm{TNF} \alpha$ levels in the CSF implicate that TNF is derived from the CNS cells. Additionally, it has been demonstrated that increased production of $\mathrm{TNF} \alpha$ preceded clinical manifestation of multiple sclerosis relapse. ${ }^{13}$

Prevention of experimental autoimmune encephalomyelitis (EAE) with

\section{PEG-TNFR1}

Prevention or inhibition of EAE in an animal model of multiple sclerosis has been achieved by neutralisation of TNF by anti-TNF antibodies or soluble TNF receptors (sTNFRs). ${ }^{14-19}$ We examined the effect of a novel TNF inhibitor, polyethylene gycol linked tumour necrosis factor receptor 1 (PEGTNFR1), on adhesion molecule expression on endothelial cells and their countermolecules on spleen cells in an attempt to dissect directly the mechanism of EAE prevention in anti-TNF treated animals. ${ }^{20}$ We provide support for the notion that TNF inhibition with PEG-TNFR1 leads to the prevention of EAE through the reduction of VCAM-1 and VLA-4 expression on endothelial cells and lymphocytes, respectively.

Two molecules of extracellular domain of TNF receptor type 1 (p55) were conjugated with polyethylene glycol chain (PEG-TNFR1). This constract proved to be effective as a TNF inhibitor in vitro and in vivo. ${ }^{21}$ PEG-TNFR1 was administered subcutaneously (sc) at a dose of 0.25 to $4.0 \mathrm{mg} / \mathrm{kg}$ in a volume of $100 \mu \mathrm{l}$ of phosphate buffered saline (PBS). This was delivered every second day on four occasions after cell transfer. PBS was injected sc into control animals with the same protocol. For treatment of EAE PEG-TNFR1 injections were performed on the first day of clinical presentation and continued every second day for eight days.

In three separate experiments, we showed that PEG-TNFR1 prevented the development of EAE in SJL/J mice (fig 1). None of animals treated with PEG-TNFR1 at a dose of $1 \mathrm{mg} / \mathrm{kg}$ and higher developed clinical signs typical of EAE. Using lower doses of PEG-TNFR1, we observed a dose response related reduction in clinical and pathological signs of EAE. At the histological level, spinal cord and brain sections from animals treated with $1.0 \mathrm{mg} / \mathrm{kg}$ of PEG-TNFR1 showed no inflammation or demyelination, characteristic features of EAE lesions.

\section{Treatment of EAE with PEG-TNFR1}

To test whether PEG-TNFR1 might influence EAE after clinical onset, we administered PEG-TNFR1 to mice adaptively transferred with MBP specific cells on the first day of clinical signs of EAE. These animals also received four sc injections of PEG-TNFR1 at a dose of $1.0 \mathrm{mg} / \mathrm{kg}$ every second day. In two experiments, we showed that animals treated with PEG-TNFR1 experienced shorter and significantly less severe disease (fig 2). The mean compound clinical score was reduced in the PEG-TNFR1 treated animals by $48 \%$ in one experiment and by $67 \%$ in the second, when measured every day over a 12 day observation period. The duration of the clinical signs was reduced by 5.3 days in animals treated with PEG-TNFR1. 

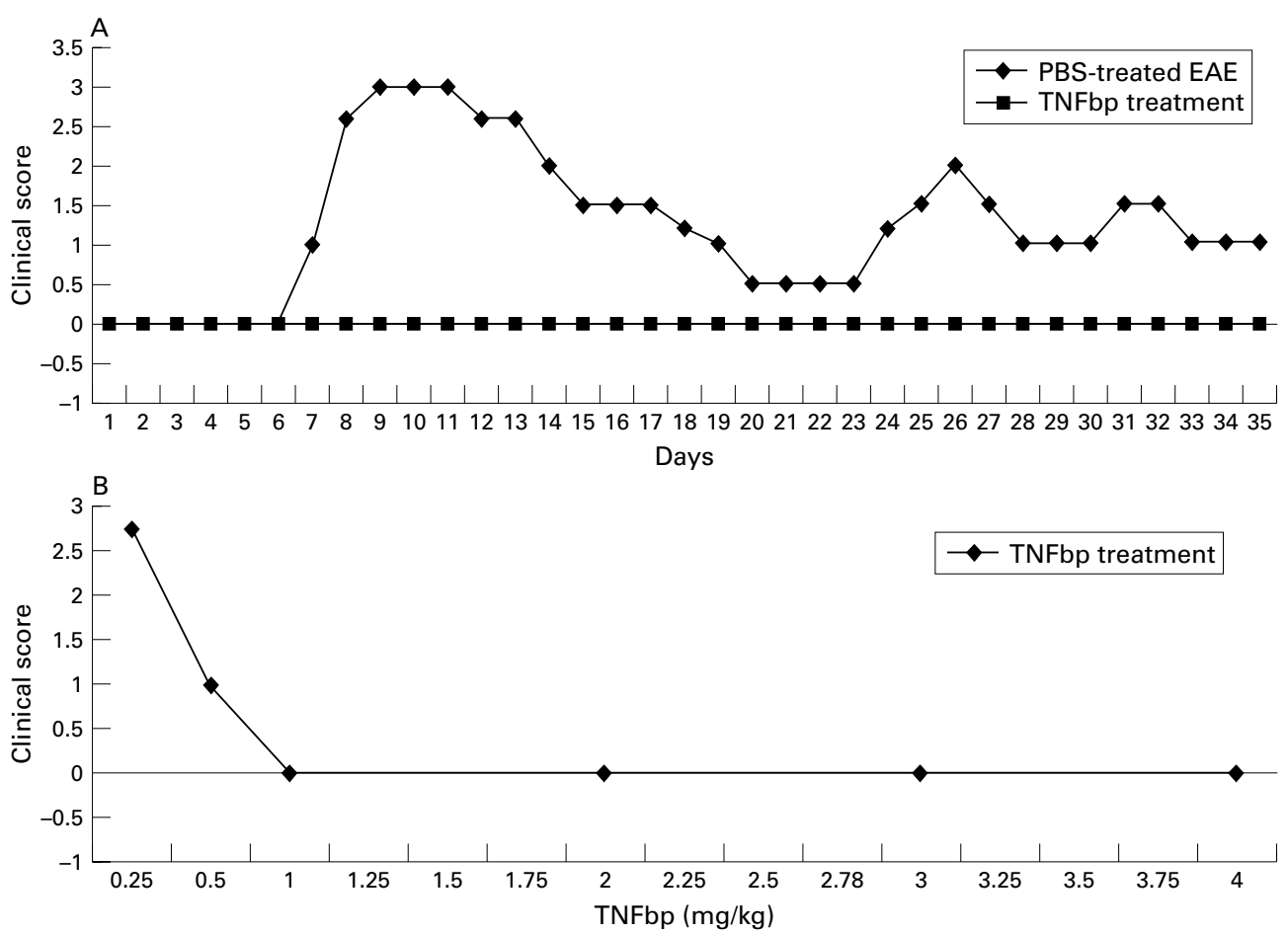

Figure 1 TNFbp suppresses the development of EAE. (A) Clinical course of SfL/F mice with EAE and mice injected with $T N F b p, 1 \mathrm{mg} / \mathrm{kg}$, four times starting on day 4 and continued every second day. Mean clinical scores of eight animals, $S D<10 \%$. (B) Dose dependent prevention of EAE with TNFbp. Mean clinical scores of eight animals, $S D<10 \%$.

\section{Mechanism of prevention and treatment of EAE with PEG-TNFR1}

ANTIGEN SPECIFIC T CELL RESPONSES.

Spleen and lymph node cells were analysed for antigen specific responses in mice treated with PEG-TNFR1 and in control EAE animals. The antigen response was assessed by cell proliferation measured by $[3 \mathrm{H}]$ thymidine uptake after 72 hours of cell culture in the presence of MBP. Spleen and lymph node cells were obtained from EAE animals at the peak of disease and at the same time point from animals treated with PEG-TNFR1 that remained healthy. Both spleen and lymph node cells from animals treated with PEG-TNFR1 proliferated to the same degree as cells from control EAE animals.
NON-ANTIGEN SPECIFIC T CELL RESPONSE

Spleen and lymph node cells obtained from EAE mice at the peak of the disease and at the same time point from PEG-TNFR1 treated mice were cultured with anti-CD3 antibody and ConA to assess non-antigen specific responses. The response was assessed by cell proliferation measured by $[3 \mathrm{H}]$ thymidine uptake in response to stimulation with antiCD3 antibody and ConA. The cells obtained from animals treated with PEG-TNFR1 showed diminished proliferation in response to ConA only with the highest dose of PEGTNFR1, $4 \mathrm{mg} / \mathrm{kg}$. Lower doses of ConA that were effective in preventing EAE did not affect spleen cell proliferation. Proliferation of spleen and lymph node cells cultured with anti-CD3

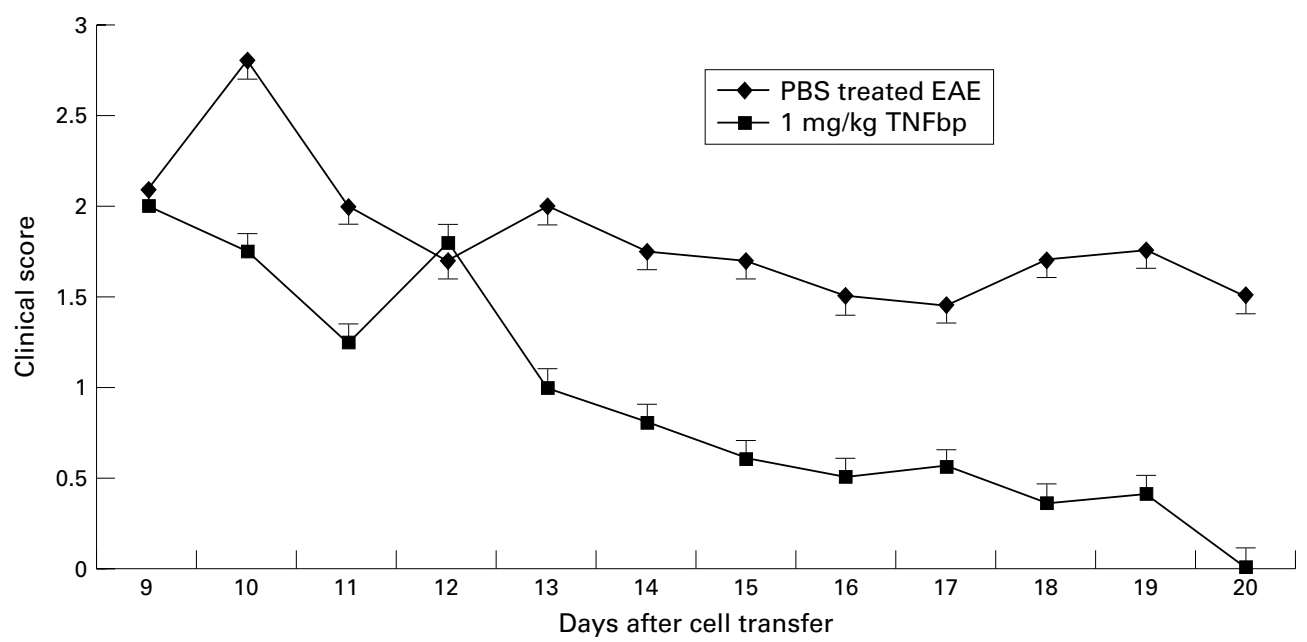

Figure $2 T$ TNFbp ameliorates the course of EAE. Each point represents the mean clinical score from six to eight mice injected four times with PBS every second day beginning at the onset of disease or with TNFbp at the same time points. 


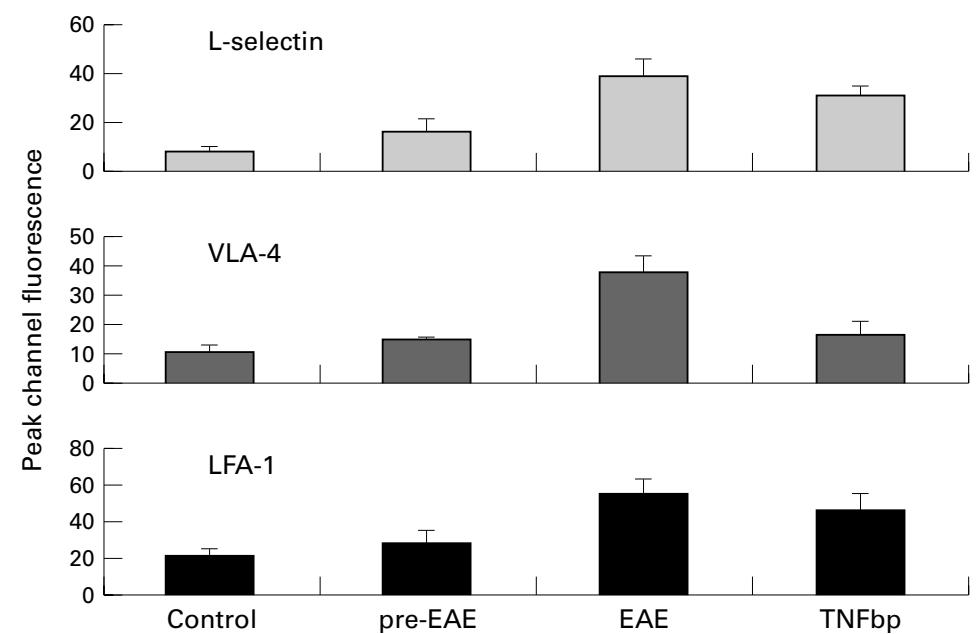

Figure 3 Effect of TNFbp on L-selectin, VLA-4 and LFA-1 expression. Spleen cells were obtained from non-immunised cells (control), from animals adoptively transferred with $M B P$ sensitised cells on day 6 (pre-EAE) and at the peak of $E A E(E A E)$ and from mice treated with $1 \mathrm{mg} / \mathrm{kg}$ TNFbp and sampled at a time point corresponding to the peak of $E A E(T N F b p)$.

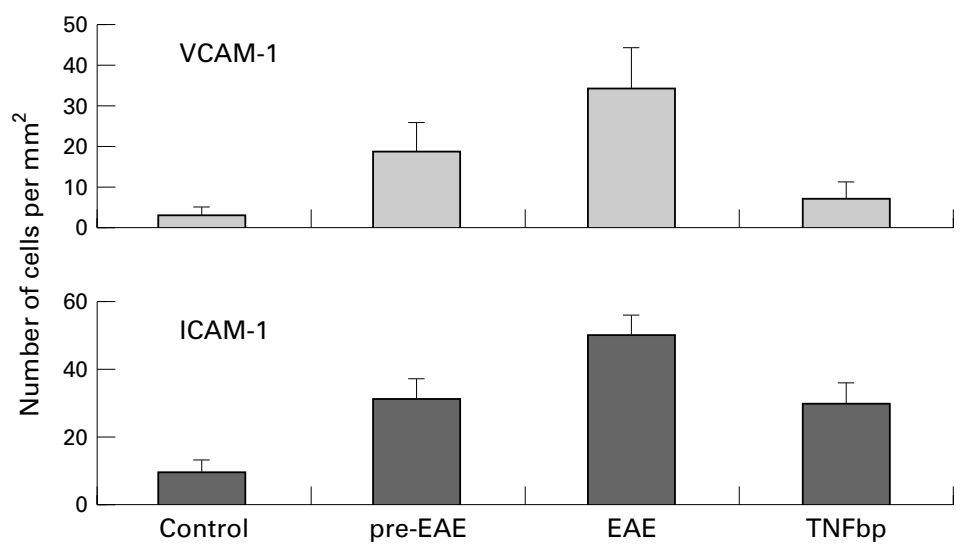

Figure 4 Effect of TNFbp on VCAM-1 and ICAM-1 expression. The bars represent number of positive cells counted from a minimum of five randomly selected frozen cross sections of lumbar spinal cord from five mice. Non-immunised mice (control), mice adoptively transferred with MBP sensitised cells and sampled on day 6 (pre-EAE), mice sampled at the peak of disease (EAE) and $1 \mathrm{mg} / \mathrm{kg}$ TNFbp treated mice sampled at a time point corresponding to the peak of EAE (TNFbp).

antibody were comparable in the PEG-TNFR1 treated mice and in control EAE mice.

\section{Adhesion molecule expression on spleen cells}

Adhesion molecule expression on spleen and lymph node cells was assessed at three time points: before transfer of encephalitogenic lymph node cells, on day 6 after cell transfer (two days before expected onset of signs), and on days $8-9$, at the peak of the disease. Parallel samples of cells were obtained from animals transferred with MBP specific cells for the induction of EAE and treated with PEGTNFR1. The expression of three molecules, L-selectin, LFA-1 and VLA-4, was assessed by direct immunofluorescence. In EAE animals, it was observed that expression of all three molecules was upregulated with development of the disease (fig 3). On day 6, a pre-clinical time point in EAE animals, the expression of L-selectin was increased twofold over control non-cell transferred animals. At the pre-clinical time point the expression of VLA- 4 and LFA-1 was increased by $34.5 \%$ and $14.3 \%$, respec- tively. At the peak of disease, the expression of all three molecules was markedly increased. L-selectin expression reached a level five times higher than in control animals, and the expression of VLA-4 and LFA-1 were increased 2.55 and 2.52, times respectively. In animals treated with PEG-TNFR1, expression of VLA-4 on spleen cells was significantly diminished and was comparable to expression at the pre-EAE time point (fig 3). The expression of LFA-1 was also diminished but to much lesser degree, whereas the expression of L-selectin was unchanged. The inhibition of VLA-4 on spleen cells in animals treated with PEG-TNFR1 showed a dose response curve within the range of 0 to $4 \mathrm{mg} / \mathrm{kg}$ of PEG-TNFR1, whereas the expression of L-selectin remained at the same level.

\section{Adhesion molecule expression in spinal cord}

To assess the expression ofther ligand molecules for VLA-4 and LFA-1 on endothelial cells, we used frozen sections of spinal cord stained by immunocytochemistry for VCAM-1 and ICAM-1. The assessment of VCAM-1 and ICAM-1 was performed at the same time as the analysis of VLA-4 and LFA-1 - that is, before transfer of MBP sensitised cells, two days before the development of EAE, and at the peak of disease. We found that expression of both VCAM-1 and ICAM-1 was strongly upregulated with the development of EAE. At day 6 after cell transfer, the expression of VCAM-1 was increased 5.14-fold over control non-cell transferred animals and continued to increase with development of the disease, reaching a 9.71-fold increase at the peak of disease. The kinetics of ICAM-1 expression showed similar pattern as VCAM-1 but the number of positive cells per $\mathrm{mm}^{2}$ was even higher than VCAM-1 positive cells. On day 6, the expression of ICAM-1 increased 3.25-fold over non-cell transferred mice and at the peak of disease, was 5.05-fold higher (fig 4). In animals treated with PEG-TNFR1, the expression of VCAM-1 was markedly reduced and at a time point corresponding to the peak of disease, was only slightly higher than in control, non-immmunised animals. The expression of ICAM-1 was also reduced in animals treated with PEG-TNFR1 in comparison to EAE mice, but the difference was not statistically significant. The number of ICAM-1 positive cells in the spinal cord of animals treated with PEG-TNFR1 was similar to the number seen at the pre-EAE time point.

Morphological study of both VCAM-1 and ICAM-1 positive cell in the CNS suggested that more than one type of cell expressed these molecules. To identify which cells expressed VCAM-1 and ICAM-1 in spinal cord, we stained the adjacent sections of spinal cord with anti-GFAP, anti-GC, anti- MAP-1 and anti-Mac-1 antibodies. It was found that VCAM-1 was mostly present on endothelial cells but some also occurred on astrocytes and microglial cells. Similarly, anti-ICAM-1 antibody stained not only endothelial cells, but glial cells of the astrocyte and microglial lineages. 
Neurons and oligodendrocytes were negative for VCAM-1 and ICAM-1. These results indicate that the major mechanism involved in the prevention of EAE with PEG-TNFR1 depends on the inhibition of expression of a pair of ligand-receptor adhesion molecules, VLA-4 and VCAM-1.

The inhibition of VCAM-1 and VLA-4 expression in the present PEG-TNFR1 treated mice with EAE correlated well with the observed lack of CNS inflammation and confirmed that VCAM-1 and VLA-4 are of primary importance during inflammatory cell homing to the CNS. TNF binding proteins were originally discovered in human urine and serum of patients with infection and neoplasmas. ${ }^{22} 23$ Sequence analysis and immunocrossreactivity revealed that TNF binding proteins were soluble forms of truncated fragments of the extracellular domains for both TNF receptors. ${ }^{24}{ }^{25}$ These truncated receptors are released from the cell surface and appear to have the ability to influence TNF levels. It has been recognised that TNF binding proteins constitutes a major physiological mechanism for regulation of TNF activity. The ability of TNFbp to change the biological activity of TNF has generated considerable interest in their potential therapeutic application. One important advantage of using TNFbp for TNF inhibition in vivo is their lack of immunogenicity when applied within the same species. Both types of soluble TNF receptor demonstrate TNF inhibiting activity but TNFR1 (p55) has been shown to be up to 30 times more potent inhibitor of TNF than TNFR2 (p75), both in vitro ${ }^{26}$ and in vivo. ${ }^{27}$ It has been postulated that soluble TNFR1 plays a more important part during conditions of more chronic TNF exposure, like multiple sclerosis, whereas sTNFR2 might be more involved during active TNF overexpression. Although the concept that sTNF receptors function as TNF inhibitors is well supported by number of studies, ${ }^{28}$ there are also data that indicate that soluble TNF receptors can function as TNF carrier proteins. Mohler et $a l^{29}$ showed that a fusion protein comprising two sTNFR2 and Fc immunoglobulin fragments increased the level of circulating TNF. The ratio of inhibition to carrier function of soluble TNF receptors might depend on the ratio between the amount of receptor and cytokine. Hale et $a l^{27}$ showed that sTNFR1 increased TNF activity, but only at a low receptor to TNF ratio. In a previous study, ${ }^{19}$ it has been shown that PEG-TNFR1 applied at a concentration of 0.5 to $4.0 \mathrm{mg} / \mathrm{kg}$, reduced the levels of TNF indicating that in the present study, we have been working within the inhibitory dose range.

\section{EAE induced in TNF gene engineering mice}

The role of TNF in EAE was investigated in animals with gene targeting. TNF was overexpressed in the CNS in transgenic mice after astrocyte or oligodendrocyte specific promotor. ${ }^{30}$ In these animals chronic inflammatory lesions have been developed in the CNS as well as demyelination. These mice developed also
EAE with greater severity than non-transgenic controls when immunised with myelin basic protein. ${ }^{31}$ Unlike non-transgenic controls, EAE has progressed to a non-abating demyelinating disease. However, animals with TNF disrupted gene subsequently to immunisation with myelin peptides have developed EAE suggesting that TNF was not needed for EAE induction. The experiments with TNF-/- mice showed, however, some differences between individual results. Liu et $a l^{32}$ using $\mathrm{C} 57 \mathrm{BL} / 6$ mice and myelin oligodendrocyte glycoprotein reported more severe EAE in TNF-/- mice whereas oth$\mathrm{ers}^{33}$ using the same mice and antigen observed a significant delay in EAE induction. In TNF-/mice immunocytochemical analysis indicated that leucocytes failed to form perivascular cuffs observed in typical EAE. These results were consistent with the TNF dependence of processes controlling initial leucocyte movement in the CNS. ${ }^{34}$ Even more controversies exists in LT-/- mice and EAE. Suen et $a l^{35}$ reported that LTa-/- mice were quite resistant to EAE and showed the negligible CNS inflammation and demyelination. LTb-/- mice were more susceptible to EAE though still less than wild type. $T$ cells from wild type transferred EAE to LTa-/- recipients implicating that $\mathrm{T}$ cell production of LTa in EAE. Frei et $a b^{36}$ reported that $129 \times \mathrm{C} 57 \mathrm{BL} / 6$ and $\mathrm{SJL} / \mathrm{J}$ mice with disrupted TNF and LTa genes developed EAE upon sensitisation with mouse spinal cord homogenate or proteolipid protein (PLP). At the histological level these mice had an intense perivascular and parenchymal infiltration of inflammatory cells. The authors concluded that TNF and LTa are not essential for the development of EAE.

\section{A multiple sclerosis trial with soluble TNF receptor 1}

The hypothesis that neutralisation of TNF may reduce or halt multiple sclerosis progression was evaluated in a phase II randomised, multicentre, placebo controlled trial with a recombinant TNFR-p55 immunoglobulin fusion protein (sTNFR-IgG p55; lenercept). ${ }^{37} \mathrm{~A}$ total of 168 patients with clinically definite or laboratory supported multiple sclerosis were randomised to 10,50 and $100 \mathrm{mg}$ of lenercept or to placebo. Patients received treatment intraveneously every four weeks for 24 weeks. Magnetic resonace imaging (MRI) was performed every four weeks during 24 weeks of treatment.

\section{MRI RESULTS}

The results of the cumulative number of newly active MRI lesions, the percentage of persistently active lesions, the percentage of active scans, and the change in burden of disease over 24 weeks of treatment were not significantly different.

CLINICAL RESULTS

The number of patients who developed exacerbation during 24 weeks of treatment were increased in the lenercept group as compared with the placebo group. In the placebo group 36 exacerbations occurred over the treatment 
period as compared with 38,47 and 49 in the multiple sclerosis patients taking 10,50 and $100 \mathrm{mg}$ of lenercept. Consequently the exacerbation rate was also increased in the lenercept group. Anti-lenercept antibodies were present in the majority of treated patients. The reason for the lenercept failure in this multiple sclerosis trial is not clear. It might be related to the lenercept molecule itself and independent of TNF neutralisation, or prompt generation of anti-lenercept antibody. The Fc-like portion of IgG might be resposiable for activation of other immune cells. The access of the lenercept to the brain has also not been assessed and it is possible that lenercept being restricted to the peripheral compartment prevented apoptosis of autoreactive $\mathrm{T}$ lymphocytes in multiple sclerosis patients. In this regard it is interesting to note that lenercept has also been shown not to be effective in reducing inflammatory changes in rheumatoid arthritis in contrast with several other anti-TNF molecules.

\section{Disbalanced in TNF receptor shedding in multiple sclerosis patients}

TNF mediates its biological effects by interacting with two distinct TNF receptors, TNFRp55 and TNFR-p75. Both of them exist in soluble form (sTNFR) and cell surface membrane bound form (TNFR). The soluble forms bind $\mathrm{TNF}$ and, in high concentration, act as its inhibitors. ${ }^{38}$ However, in lower concentration, soluble receptors can prolong biological half life time of TNF activity. ${ }^{39}$ The sTNFRs are generated by shedding the extracellular domain from the membrane bound form of a complete receptor. The mechanism of receptor shedding is mediated by metalloproteinase, probably similar to the recently cloned metalloproteinase TACE belonging to ADAM family, which cleaves TNF from the pro-TNF molecule. ${ }^{40}$ Regulation of TNF receptor shedding represents a sensitive mechanism controlling $\mathrm{TNF}$ availability. Disturbances in TNF receptor shedding might be linked with TNF induced immune events in autoimmune disease, including multiple sclerosis. The levels of sTNFRs in serum and CSF of MS patients have increased compared with non-multiple sclerosis controls. ${ }^{41}{ }^{42}$ To gain additional insight into the mechanisms of TNF biological availability, we measured the TNFR shedding by peripharal blood mononuclear cells (PBMC), monocytes, and lymphocytes in multiple sclerosis patients and controls. ${ }^{43}$

Twenty six patients with clinically definitive multiple sclerosis, according to Poser criteria, were included in this study. Thirteen patients had chronic progressive (CP) multiple sclerosis, and 13 patients had remitting-relapsing (RR) type of the disease. In addition to the clinical assessment, MRI was performed within two months before testing to confirm the diagnosis. The control group consisted of 13 healthy volunteers of the same age and sex as multiple sclerosis patients. We also included a group of patients with other inflammatory neurological diseases (OND), which consisted of the following: neuroborreliosis (4), neuro- sarcoidosis (1), CNS vasculitis (1), viral encephalitis (1), tuberculous encephalomeningitis (1), and bacterial meningitis (3).

All populations of cells, PBMC, monocytes and lymphocytes, isolated from patients and controls according to standard procedures were resuspended and cultured in RPMI 1640 medium for up to 72 hours. The lymphocyte and monocyte phenotype of isolated cells was determined by cytofluorographic analysis. To investigate the regulation of sTNFR generation, we applied unspecific stimulation with phytohaemagglutinin (PHA) at a concentration of $10 \mu \mathrm{g} / \mathrm{ml}$ and liposaccharide (LPS), 10 $\mu \mathrm{g} / \mathrm{ml}$. After 24, 48 and 72 hours of culture, the supernates were collected. To assess generation of sTNFRs, ELISA was developed. Microwells consisting of 96 well, flat bottomed plate were coated with anti-sTNFR antibody, and then the supernatants from cell cultures were added in triplicate. Anti-TNFR antibodies (clone utr-4 for sTNFR-p75 and clone htr-20 for sTNFR-p55) were a generous gift from $\mathrm{Dr}$ Werner Lesslauer (Hoffman-La Roche, Basel, Switzerland). Next, TNF $\alpha$ conjugated with horseradish peroxidase was added and incubated for 24 hours. After that, the plate was incubated with $\mathrm{H}_{2} \mathrm{O}_{2}$ and tetramethylbenzidine for 10 minutes, and the reaction was stopped with $1 \mathrm{~mol} / 1$ of sulphuric acid. The absorbance of the coloured reaction product was measured at $450 \mathrm{~nm}$. The lower limit of detection was $0.005 \mathrm{ng} / \mathrm{ml}$. The interassay variability was $8.2 \%$, and intra-assay variability was $5.7 \%$.

To investigate protein kinase involvement in TNF receptor shedding, a specific protein kinase C inhibitor, staurosporine (1 to 100 $\mathrm{nmol} / \mathrm{l}$ ), was added before stimulation with PHA or LPS.

To assess TNF production by PBMC and correlate it with shedding of TNFRs, we used an ELISA (R\&D, Wiesbaden, Germany) according to manufacturer's protocol. The interassay variability was $5.4 \%$, and intra-assay variability was $4.4 \%$. The lower limit of detection was $4.4 \mathrm{pg} / \mathrm{ml}$.

STNFR-P75 SHEDDING

Spontaneous generation of sTNFR-p 75 from PBMC of all groups of multiple sclerosis patients was significantly higher than in healthy volunteers $(0.6 \mathrm{ng} / \mathrm{ml})$ and in the OND group $(0.43 \mathrm{ng} / \mathrm{ml}$ ) (fig 5). The highest shedding was detected in the CPMS group: $1.7 \mathrm{ng} / \mathrm{m}$ (p $<0.01$ ). In RRMS patients in relapse, sTNFRp75 generation was $1.3 \mathrm{ng} / \mathrm{ml}(\mathrm{p}<0.01)$, and in RRMS patients in remission, it was slightly lower $(1.1 \mathrm{ng} / \mathrm{ml})$ (fig 5).

After stimulation with PHA, in all investigated groups, generation of sTNFR-p75 from PBMC was increased compared with unstimulated cells. The highest increase in sTNFR-p75 generation was observed in the control group (4.2-fold over unstimulated cells); however, the absolute values of sTNFR-p75 level after PHA stimulation in healthy volunteers $(2.1 \mathrm{ng} / \mathrm{ml})$ and OND patients $(1.75 \mathrm{ng} / \mathrm{ml})$ still were significantly lower than in multiple sclerosis-RR patients in relapse $(3.6 \mathrm{ng} / \mathrm{ml})$. In the RRMS remission and multiple sclerosis-CP 

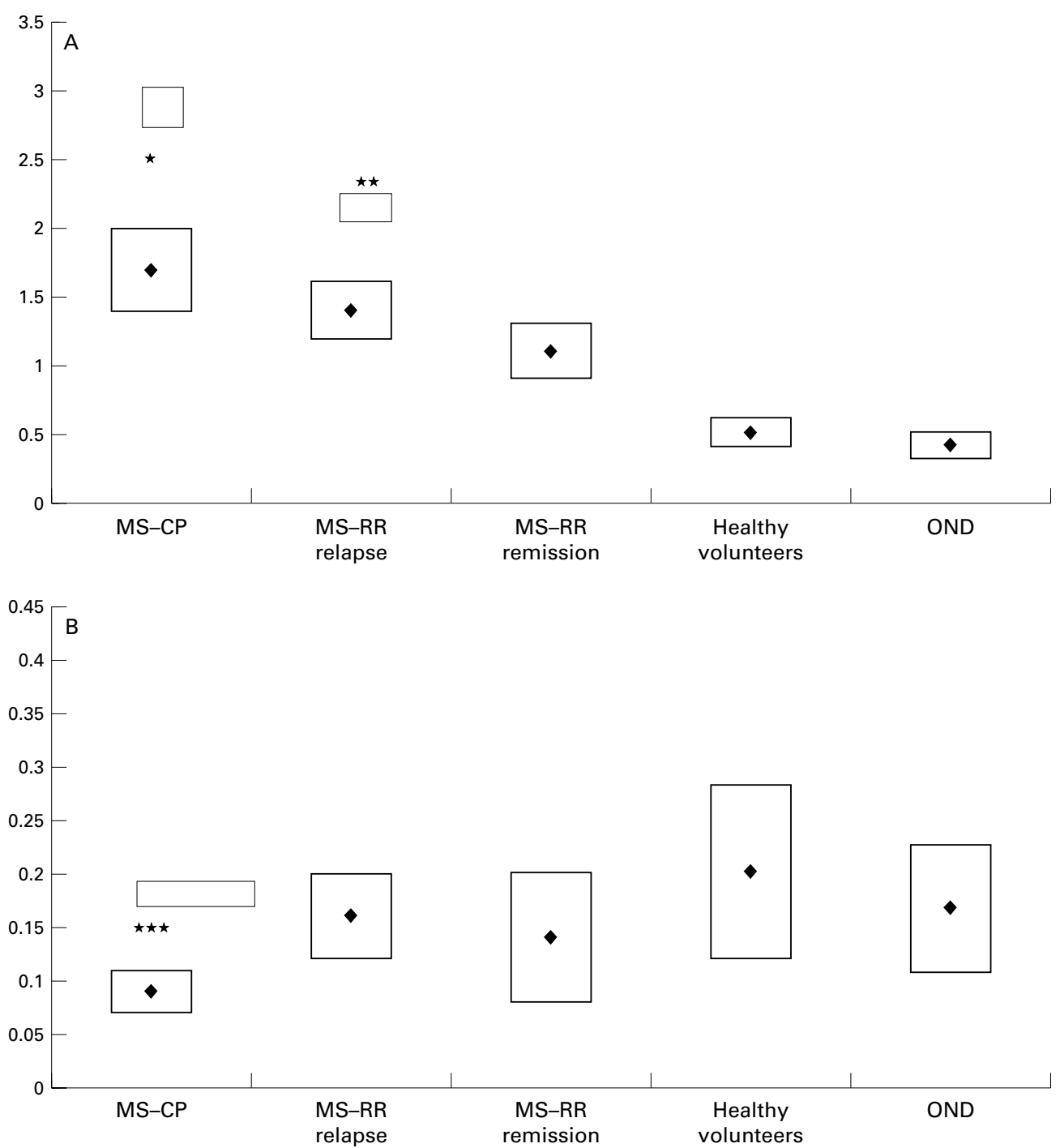

Figure 5 Mean shedding of TNFR-p75 (A) and TNFR-p55 (B) from peripheral blood mononuclear cells (PBMC). The boxes and whiskers represent standard deviation, standard error, and the mean value. ${ }^{\star} T N F R-p 75$ shedding in chronic progressive multiple sclerosis $(M S-C P)$ was higher than in healthy volunteers $(p<0.01)$ and in the other neurological diseases (OND) group $(p<0.01) ; * \star$ TNFR-p 75 shedding in relapsing-remitting multiple sclerosis (MS-RR) in relapse was higher than in healthy volunteers $(p<0.01)$ and the OND group $(p<0.01)$; $* \star * T N F R-p 55$ shedding in $M S-C P$ was lower than in healthy volunteers $(p<0.001)$ and in the OND group $(p<0.001)$.

groups, the shedding of TNFR-p75 also was lower $(2.3 \mathrm{ng} / \mathrm{ml}$ and $2.7 \mathrm{ng} / \mathrm{ml}$, respectively) than in healthy volunteers and OND groups, but the differences did not reach statistical significance.

After stimulation with LPS, generation of sTNFR-p75 also was increased but not as much as after PHA stimulation. Again, significantly higher generation was observed in RRMS patients in relapse $(2.3 \mathrm{ng} / \mathrm{ml})$. The level of sTNFR-p75 in the healthy volunteer group was $1.3 \mathrm{ng} / \mathrm{ml}(\mathrm{p}<0.02)$.

Spontaneous shedding of sTNFR-p75 from lymphocytes of RRMS patients was much lower than from PBMC (0.4 versus $1.3 \mathrm{ng} / \mathrm{ml}$ ) but still was twofold higher than in healthy volunteers $(0.2 \mathrm{ng} / \mathrm{ml})$. After PHA stimulation, sTNFR-p75 generation was increased; however, there was no difference between RRMS patients $(1.0 \mathrm{ng} / \mathrm{ml})$ and healthy volunteers $(1.0 \mathrm{ng} / \mathrm{ml})$.

Spontaneous generation of sTNFR-p75 in monocyte culture in RRMS patients (0.4 $\mathrm{ng} / \mathrm{ml}$ ) was insignificantly different from the healthy volunteer group $(0.5 \mathrm{ng} / \mathrm{ml})$. After monocyte stimulation with LPS, sTNFR-p75 generation was slightly higher but remained at a similar level in RRMS patients $(0.6 \mathrm{ng} / \mathrm{ml})$ and healthy volunteers $(0.7 \mathrm{ng} / \mathrm{ml})$.

STNFR-P55 SHEDDING

Spontaneous generation of sTNFR-p55 from PBMC of all groups of multiple sclerosis patients was lower than in the healthy volunteer group $(0.24 \mathrm{ng} / \mathrm{ml})$. The lowest level of sTNFR-p55 was in CP-multiple sclerosis patients $(0.09 \mathrm{ng} / \mathrm{ml} ; \mathrm{p}<0.001)$. In RRmultiple sclerosis patients in relapse, the sTNFR-p55 level was $0.16 \mathrm{ng} / \mathrm{ml}$, and in RR-MS patients in remission, $0.14 \mathrm{ng} / \mathrm{ml}$. In OND patients, the shedding was $0.165 \mathrm{ng} / \mathrm{ml}$ (fig 5).

After PHA and LPS stimulation, sTNFRp55 generation remained at the level of unstimulated cells in all investigated groups 
and continued to be lower in the multiple sclerosis groups compared with controls.

Spontaneous generation of sTNFR-p55 from lymphocytes of RRMS patients (0.004 $\mathrm{ng} / \mathrm{ml}$ ) was four times lower than in healthy volunteers $(0.025 \mathrm{ng} / \mathrm{ml})$. After PHA stimulation, sTNFR-p55 generation in multiple sclerosis patients remained lower than in controls.

Spontaneous generation of sTNFR-p55 in monocytes of RRMS patients $(0.017 \mathrm{ng} / \mathrm{ml})$ was significantly lower than in healthy volunteers $(0.1 \mathrm{ng} / \mathrm{ml})$. After LPS stimulation, sTNFR-p55 generation remained at the level of unstimulated cells for both multiple sclerosis patients $(0.011 \mathrm{ng} / \mathrm{ml})$ and in the control group $(0.13 \mathrm{ng} / \mathrm{ml})$.

KINETICS OF TNFR SHEDDING

Considering that the difference in TNFR shedding between multiple sclerosis patients and controls may not necessarily result from the difference in the total amount of receptor shed but rather from the difference in the kinetics of this shedding, we performed a kinetic study by measuring sTNFR-p75 and sTNFR-p55 levels at 24, 48 and 72 hours of culture. We did not see a significant difference in the kinetics of shedding of both receptors between multiple sclerosis patients and controls.

TNF PRODUCTION

In parallel cultures of PBMC obtained from multiple sclerosis patients and controls, we measured the production of TNF. Spontaneous production in RR-multiple sclerosis patients in relapse was up to fourfold higher than in healthy volunteers: 337.3 versus $83.1 \mathrm{pg} / \mathrm{ml}$. PHA and LPS stimulation increased production of TNF in both multiple sclerosis patients and controls, and the concentrations were, respectively, 597.8 versus $432.1 \mathrm{pg} / \mathrm{ml}$ for LPS and 490.7 versus $192.0 \mathrm{pg} / \mathrm{ml}$ for PHA. TNF production in RR-multiple sclerosis remission and CP-multiple sclerosis groups was lower, but not significantly, from the RR-multiple sclerosis relapse group. Between healthy volunteers and the OND group, there were no significant differences noted in TNF production.

\section{TNF-TNFR RATIO}

Considering that TNF can influence the shedding of its own receptors, we related individual levels of TNF to the level of sTNFRs. The results demonstrate that the TNF-sTNFR-p75 ratio in multiple sclerosis was not significantly different from both control groups, suggesting that TNF correlates with the shedding of TNFR-p75. The TNF-sTNFR-p55 ratio was significantly higher in the multiple sclerosis-RR group than in both control groups, suggesting that high TNF levels correlate with lower levels of sTNFR-p55, which might have resulted from internalisation of TNFR-p55.

PROTEIN KINASE C INHIBITION

Staurosporine at a concentration of $100 \mathrm{nmol} / 1$ completely inhibited shedding of TNFR-p75 from PBMC of both multiple sclerosis patients and healthy controls. Shedding of TNFR-p55 was unaffected by staurosporine treatment.

In summary we observed a significant distortion in generation of both soluble TNF receptors. Whereas the TNFR-p55 was shed at lower rate compared with healthy volunteers, the shedding of TNFR-p75 was significantly higher in multiple sclerosis patients. Disturbances in TNFR shedding might contribute to the distortion of a fine balance between circulating TNF and its natural inhibitors in multiple sclerosis.

\section{Conclusions}

To fully determine the role and significance of TNF family genes in EAE and multiple sclerosis requires further studies. A bulk of data suggested that TNF and related cytokines might be of primary importance in neurimmunology of demyelinating processes. These data included results of experiments in vitro with myelinated cultures as well as with pure glial cell cultures demonstrating very potent and selective TNF cytotoxicity against myelin and oligodendrocytes. The results obtained in EAE with TNF neutralising molecules strongly supported the hypothesis that TNF plays a part in inflammatory demyelination. Several studies proved that using anti-TNF antibodies, soluble TNF receptors or other type of TNF inhibitors it was possible to control both EAE develoment as well as EAE treatment. However, data obtained using mice models with TNF disrupted gene gave very confusing and contradictory results. Some authors were able to induce EAE and have not seen any difference in disease to wild type animals whereas others observed either significant delay in EAE development or resistance to EAE in TNF/LT -/mice. Further studies with more modern TNF gene disruption models like conditional knock outs are needed in this regard. The only attempt to apply TNF inhibitor, TNF fusion IgGprotein, to multiple sclerosis treatment has failed. However, several questions remained open after that study. Was the construct used the most optimal one in TNF inhibiting? Does it penetrate the CNS? How does it affect lymphocyte apoptosis? Unfortunately, despite the above concerns, the negative results with lanercept lower the enthusiasm for the anti-TNF treatment approach in multiple sclerosis but it would be premature to leave this treatment option too early.

\footnotetext{
Funding: this work was supported by $\mathrm{KBN}$ grant $4 \mathrm{P} 05 \mathrm{~A}$ Fundin

1 Waksman $\mathrm{BH}$. Mechanisms in multiple sclerosis. Nature 1985;318:104-5.

2 Tracey KJ, Wei H, Mannogue KR, et al. Cachectin/tumor necrosis factor induces cachexia, anemia, and inflammation. J Exp Med 1988;167:1211-27.

3 Yokota S, Geppert TD, Lipsky PI. Enhancement of antigenand mitogen- induced human $T$ lymphocyte proliferation by tumor necrosis factor. J Immunol 1988;140:531-8.

4 Ranges GE, Figari IS, Espevik T, Palladino MA. Inhibition of cytotoxic $\mathrm{T}$ cell development by transforming growth factor-beta and reversal by recombinant tumor necrosis factor alpha. J Exp Med 1987;166:991-9.

5 Selmaj K, Raine CS. Tumor necrosis factor mediates myelin and oligodendrocyte damage in vitro. Ann Neurol 1988;23: and olig $339-46$.

6 Selmaj K, Raine CS, Farooq M, Noorton WT, Brosnan CF. Cytokine cytotoxicity against oligodendrocytes. Apoptosis induced by lymphotoxin. J Immunol 1991;147:1522-9.
} 
7 Selmaj K, Farooq M, Norton WT, Raine CS, Brosnan CF Proliferation of astrocytes in vitro in response to cytokines. Proliferation of astrocytes in vitro in response to cytokines. A primary role

8 Selmaj K, Raine CS, Cannella B, Brosnan CF. Identification of lymphotoxin and tumor necrosis factor in multiple sclerosis lesions. J Clin Invest 1991;87:949-54.

9 Peter JB, Boctor FN, Tourtellotte WW. Serum and CSF levels of IL-2, sIL-2R, TNF-a and IL-1b in chronic progressive multiple sclerosis. Expected lack of clinical utility. Neurology 1991;41:121-3.

10 Franciotta DM, Grimaldi LME, Martino GV, et al. Tumor nrcrosis factor in serum and cerebrospinal fluid of patients with multiple sclerosis. Ann Neurol 1989;26:787-9.

11 Hauser SL, Doolittle TH, Lincoln R, Brown RH, Dinarello CA. Cytokine accumulation in CSF of multiple sclerosis patients: frequent detection of interleukin-1 and tumor necrosis factor but not interleukin-6. Neurology 1990;40: necrosis

12 Sharief MK, Hentges R. Association between tumor necrosis factor-a and disease progression in patients with multisis factor-a and disease progression in patients
ple sclerosis. N Engl J Med 1991;325:467-72.

13 Beck J, Rondot L, Catinot L, Falcoff E, Kirchner H, Wietzerbin J. Increased production of interferon gamma and tumor necrosis factor precedes clinical manifestation in multiple sclerosis: Do cytokines tigger exacerbation? Acta Neurol Scand 1988;78:318-23.

14 Selmaj K, Raine CS, Cross AH. Anti-tumor necrosis factor therapy abrogates autoimmune demyelination. Ann Neurol 1991;30:694-700.

15 Ruddle NH, Bergaman CM, McGrath ML, et al. An antibody to lymphotoxin and tumor necrosis factor prevents transfer of experimental allergic encephalomyelitis. J Exp Med 1990;172:1193-200.

16 Genain CP, Roberts T, Davis RL, et al. Prevention of autoimmune demyelination in nonhuman primates by a cAMP-specific phosphodiesterase inhibitor. Proc Natl Acad Sci USA 1995;92:3601-5.

17 Baker D, Butler D, Scallon BJ, O Neil JK, Turk JL, Feldman M.Control of established experimental allergic encephalomyelitis by inhibition of tumor necrosis factor (TNF) myelitis by inhibition of tumor necrosis factor (TNF) activity within the

18 Sommer N, Loschmann PA, Northoff GH, et al. The antidepressant rolipram suppresses cytokine production and prevents autoimmune encephalomyelitis. Nature Med 1995; $1: 244-8$.

19 Selmaj K, Papierz W, Glabinski A, Kohno T. Prevention of chronic relapsing experimental autoimmune encephalomyelitis by soluble TNF receptor I. J Neuroimmuno 1995;56:135-41.

20 Selmaj K, Walczak A, Mycko M, Berkowicz T, Kohno T, Raine CS. Suppression of experimental autoimmune encephalomyelitis with a TNF binding protein (TNFbp) correlates with down-regulation of VCAM-1/VLA-4. Eur J Immunol 1998;28:2035-44.

21 Kohno T, Brewer MT, Baker SL, et al. A second tumor necrosis factor receptor gene product can shed a naturally
occuring tumor necrosis factor inhibitor. Proc Natl Acad occuring tumor necrosis

22 Seckinger P, Idaaz S, Dayer JM. A human inhibitor to tumor necrosis factor alpha. J Exp Med 1988;167:1511-20.

23 Engelmann H, Aderka D, Rubinstein M, Rotman D, Wallach D. A tumor necrosis factor binding protein purified to homogeneity from human urine protects cells from tumor necrosis factor toxicity. J Biol Chem 1989;264 11974-80.

24 Engelmann H, Novick D, Wallach D. Two tumor necrosis binding protein purified from humane urine: Evidence for immunological cross-reactivity with cell surface tumor necrosis factor receptors. J Biol Chem 1990;265:1531-8.

25 Seckinger P, Zhang J-H, Hauptmann B, Dayer J-M. Characterization of a tumor necrosis factor alpha (TNF alpha) inhibitor: evidence of immunological cross-reactivity with the TNF receptor. Proc Natl Acad Sci USA 1990;87: $5188-94$
26 Evans TJ, Moyes D, Carpenter A, et al. Protective effect of $55 \mathrm{kD}$ but not $75 \mathrm{kD}$ soluble TNF receptor-IgG fusion proteins in an animal model of Gram-negative sepsis. J Exp Med 1994;180:2173-81.

27 Hale KK, Smith CG, Baker SL, et al. Multifunctional regulation of the biological effects of TNFa by the soluble type I and type II TNF receptors. Cytokine 1995;7:26-37.

28 Fernandez-Botran R, Chilton PM, Ma Y. Soluble cytokine receptors: Their roles in immunoregulation, disease, and therapy. Adv Immunol 1996;63:269-88.

29 Mohler KM, Torrance DJ, Smith CA, et al. Soluble tumor necrosis factor (NF) receptors are effective therapeutic agents in lethal endotoxemia and function simultaneously as both TNF carriers and TNF antagonists. J Immunol 1993;151:1548-55.

30 Probert L, Akassoglou K, Pasparakis M, Kontogeorgos G, Kollias G. Spontaneous inflammatory demyelinating disease in transgenic mice showing central nervous systemspecific expression of tumor necrosis factor-a. Proc Natl Acad Sci USA 1995;92:11294-8.

31 Taupin V, Renno T, Bourbonniere L, Peterson AC, Rodriguez M, Owens T. Increased severity of experimental autoimmune encephalomyelitis, chronic macrophage/ microglial reactivity, and demyelination in transgenic mice producing tumor necrosis factor-a in the central nervous system. Eur J Immunol 1997;27:905-13.

$32 \mathrm{Liu} \mathrm{J}$, Marino MW, Wong G, et al. TNF is a potent anti-inflammatory cytokine in autoimmune-mediated demyelination. Nature Med1998;1:78-83.

33 Korner H, Riminton DS, Strickland DH, Lemckert FA, Pollard JD, Sedgwick JD. Critical points of tumor necrosis factor action in central nervous system autoimmune inflammation defined by gene targeting. J Exp Med 1997;9:1585-90.

34 Kassiotis G, Pasparakis M, Kollias G, Probert L. TNF accelerates the onset but does not alter the incidence and severity of myelin basic proteininduced experimental autoimmune encephalomyelitis. Eur J Immunol 1999;29: 774-80.

35 Suen WE, Bergman ChM, Hjelmstrom P, Ruddle NH. A critical role for lymphotoxin in experimental allergic encephalomyelitis. J Exp Med 1997;8:1233-40.

36 Frei K, Eugster HP, Bopst M, Constantinescu CS, Lavi E, Fontana A. Tumor necrosis factor a and lymphotoxin a are not required for induction of acute experimental autoim mune encephalomyelitis. J Exp Med 1997;12:2177-82.

37 The Lenercept Mulitple Sclerosis Study Group and The University of British Columbia MS/MRI Analysis Group. TNF neutralization in MS results of a randomized, placebo-controlled multicenter study. Neurology 1999;53: $457-65$.

38 Loetscher H, Steinmetz M, Lesslauer W. Tumor necrosis factor: receptors and inhibitors. Cancer Cells 1991;3: 221-6.

39 Aderka D, Engelmann H, Maor Y, Brakebusch, Wallach D. Stabilization of the bioactivity of tumor necrosis factor by its soluble receptors. J Exp Med 1992;175:323-9.

40 Black RA, Rauch CT, Kozlovsky CJ, A metalloproteinase disintegrin that releases TNF-alpha from cells. Nature 1997;385:733-6.

41 Tsukada N, Matsuda M, Miyagi K, Yanagasiwa N. Increased levels of intercellular adhesion molecul-1 (ICAM-1) and tumor necrosis factor receptor in the cerebro-spinal fluid of patients with multiple sclerosis. Neurology 1993;43:2679-82

42 Tsukada N, Matsuda M, Miyagi K, Yanagasiwa N. Increased levels of soluble tumor necrosis factor receptor in patients with multiple sclerosis and HTLV-1 associated myelopathy. J Neuroimmunol 1994;52:33-40.

43 Jurewicz AM, Walczak AK, Selmaj KW. Shedding of TNF receptors in multiple sclerosis patients. Neurology 1999; 53:1409-14. 